\title{
Benedito Calixto:
}

um olhar "romântico" sobre a

paisagem paulista

Dalmo de Oliveira Souza e Silva ${ }^{7}$

DOI 10.20396/eha.vil4.3442

As pinturas de Calixto são testemunhos de um momento de transição (...). A precisão no registro de vistas, onde a arquitetura comparece, de panorâmicas das cidades e de seus confins, de paisagens litorâneas, remete a um passado recente, revelando cenários hoje quase irreconhecíveis (...). Tempo congelado em imagens surpreendentes na constatação de que assim foi. ${ }^{2}$

Em 1917, Affonso de Escragnoloe Taunay (1876-1954) assume a direção do Museu Paulista, criado em 1893, cuja fundação é, sobretudo, resultante de injunções políticas republicanas e da consolidação de um novo ciclo econômico. À época, o novo museu tem como missão o fortalecimento do regime republicano, das oligarquias e da elite cafeeira. Nos novos tempos inaugurados pelo século XX, o legado paulista, rememorado pelas pesquisas do Museu Paulista, seria o marco fundante da história oficial do País. Sob essas circunstâncias, Taunay às vésperas das comemorações do centenário de independência do Brasil, estrutura a seção de História Nacional e desenvolve um projeto de exposições históricas, especialmente para a efeméride. São 16 salas expositivas, sendo que quatro delas são dedicadas à história de São Paulo e dessas, duas "reconstituem" a cidade em meados do século XIX.

Para a formação de uma delas, a denominada Antiga Iconografia Paulistana, Taunay encomendou telas a óleo a pintores, tais como, Benedito Calixto de Jesus (1853-1927), José Wasth Rodrigues (1891-1957), Henrique Manzo (1896-1982), entre outros. Todos os pintores têm como modelo as fotografias de Militão Augusto de Azevedo (1837-1905), que registra a cidade em dois momentos distintos: 1862 e 1887. O fotógrafo faz suas primeiras imagens, entre 1862 e 1863, sendo que quase todas as ruas da, então, província de São Paulo, surgem no trabalho. Já em 1887, Militão fotografa as mesmas ruas sob os mesmos ângulos - no fundo, um testemunho em dois tempos sobre a evolução

\footnotetext{
1 Professor Titular da Universidade Metodista de São Paulo. Doutor em Artes Visuais pela Escola de Comunicações e Artes da Universidade de São Paulo.

2 OLIVEIRA, Maria Alice Milliet de. Benedito Calixto: memória paulista. In: BENEDITO Calixto: memória paulista. São Paulo: Projeto Banespa, Pinacoteca do Estado, 1990, p. 19.
} 
urbanística da cidade.

Afora as telas vindas dos modelos fotográficos de Militão, na coleção do Museu Paulista, merece destaque a tela Inundação da Várzea do Carmo, 1892, de Benedito Calixto. A pintura não integra a série de encomendas que tem as fotografias de Militão como modelo, porém está presente na sala dedicada à Antiga Iconografia Paulistana. Essa pintura é uma cena panorâmica, vista de uma colina, provavelmente da região do Pátio do Colégio. Na tela, o pintor recria minuciosamente a cheia da Várzea do Carmo e o seu transbordamento, mostrando o curso original do Rio Tamanduateí; ele coloca em primeiro plano o Mercado Municipal; à esquerda, a fábrica de tecidos de Major Diogo e ao centro as casas, onde hoje seria a Rua 25 de Março.

Vista como "verdadeiro" registro histórico, a Inundação da Vázea do Carmo apresenta características relevantes para a construção da visualidade do passado colonial da cidade de São Paulo notemos que, tradicionalmente, a pintura tem grande notoriedade no universo dos museus, pois é percebida a partir do estatuto de peça autêntica. Além disso, a monumentalidade (a tela apresenta dimensões de $125 \times 400 \mathrm{~cm}$ ), o forte vínculo com o desenho, o detalhamento, os planos e as formas bem definidas deixam a imagem mais descritiva e dá a aparência de estar mais próxima da verossimilhança. Recordemos ainda que as grandes dimensões incentivam a observação de pequenas unidades dentro do conjunto. Esses fatores, somados ao aumento do grau de compreensão e familiaridade do púbico, contribuem para a opção de Taunay em transformar as fotografias de Militão $(18 \times 24 \mathrm{~cm})$ para a escala das pinturas a óleo de Calixto e outros pintores (em média $60 \times 60 \mathrm{~cm})^{3}$. A decisão de Taunay de conceber a sala Antiga Iconografia Paulistana e convidar artistas - tal como Benedito Calixto - corresponde a um propósito que marca para sempre a escrita da história nacional.

Ademais de suasligações com Taunay eo Museu Paulista, o pintor-historiador Benedito Calixto é membro do Instituto Histórico Ceográfico de São Paulo (IHCSP), desde 1895, empenhando-se na representação da história e na "invenção" de uma paisagem, sustentada por vasta documentação para a confecção de suas pinturas. À essa condição acrescente-se a formação atípica de Calixto: ele não passa pelos ensinamentos da Academia de Belas-Artes no Rio de Janeiro - como a maioria dos pintores do período. Seu ofício surge da aprendizagem em ateliês e em escolas para artes aplicadas paulistas. Ele também passa por um breve período de ensinamentos na França, em 1883, financiado pela Associação Comercial Santista. Não tendo estudos formais em belas-artes, Calixto recorre 
às suas relações sociais e políticas para a obtenção de encomendas e vendas de trabalhos - algo perfeitamente possível, uma vez que o mercado de artes recebe atenções de instituições seculares, religiosas e da elite emergente naquele período.

No regresso dos estudos em Paris, Calixto traz consigo a máquina fotográfica-instrumental que Ihe acompanha na realização de muitos trabalhos. Entusiasmado pelos recursos da objetiva, Calixto torna-se pioneiro em pintar a partir de fotos. À época, o emprego da imagem técnica na pintura de Gustave Coubert (1819-1877), por exemplo, transpôs à pintura a representação exata do que via, em detrimento ao romantismo que vigorava entre os pintores naquele momento. A maioria dos pintores busca referências à realidade externa de seus modelos (pessoas, objetos ou paisagens). No ofício de Benedito Calixto, o registro fotográfico serve à pintura, especialmente na produção de suas paisagens. Esses registros, realizados por ele ou por outros fotógrafos, são empregados como modo de estudo da composição da paisagem. Porém, mesmo essa carga documental presente no repertório de Benedito Calixto, ou seja, a preocupação com os aspectos reais, não impede o pintor de corrigir o desenho e a perspectiva obtidos pela lente fotográfica.

Assinala-se, nesse ponto, uma das características mais densas da pintura acadêmica: o respeito aos padrões de beleza impostos pela Academia de Belas-Artes. Por isto, o artista não deve imitar a realidade. Ele deve recriar a beleza ideal em suas obras por meio da inspiração dos clássicos. No caso do repertório de Calixto, acentuado por seu gosto regionalista, entram na composição das telas a abordagem positivista dos dados históricos e a vontade de retratar uma paisagem um tanto idílica, com tons terrosos, com "ares românticos" e idealizados. Pela conduta de Calixto percebe-se, então, que na virada do século XIX para o XX, a arte brasileira se vê marcada não somente pela tradição do neoclássico, mas também pelo romantismo e pela pintura "juste milieu", ou seja, existe um espelhamento dos debates e movimentos que os artistas brasileiros vivem na capital francesa e que traduzem para o ambiente nacional. A possibilidade do "meio termo" dava aos pintores desse período os instrumentais para a busca de "um moderno" que diverge ou até mesmo mistura-se, numa perspectiva academizante, às vanguardas europeias.

A produção das paisagens paulistas também está imersa no imaginário vindo dos artistasviajantes dos séculos XVI a XVIII. O repertório desses artistas serve como fonte de pesquisa iconográfica aos estudos de Taunay para formação da coleção do Museu Paulista, bem como aos pintores contratados para a execução das paisagens paulistas. Porém, as paisagens feitas pelos artistas-viajantes sustentam-se pela investigação ligada à botânica e em especial relacionada às ciências naturais que anseiam a apreensão da Terra Brasilis, vista como o paraíso tropical. Dos 
pequenos "Carnet de route" ao modelo das "Vedutti" as paisagens tornam-se o gênero de maior predileção desses artistas, cujo objetivo é divulgar, classificar e dominar a natureza exuberante, através de preciosos preceitos tão ao gosto da Academia.

A ideia de que a apreciação da natureza se faz presente nas pinturas de paisagens, tema muito recorrente na formação dos artistas que passam pelas lições das academias e, que Benedito Calixto não poderia de deixar de desenvolver este gosto tão popular e tão presente nos salões e exposições que vigoravam no período. É por meio desta paixão pela luz que a paisagem se liga à história da pintura do século XIX. Segundo Clark:

Os grandes pintores imaginativos dos princípios do século XVI tinham um feito dos efeitos do fogo e dos crepúsculos, as principais armas com que assaltavam as nossas emoções e, com grandes poderes de observação e de memória, realizavam efeitos de luz que nunca poderiam ter sido conseguidos por meio de uma pintura factual ${ }^{4}$.

Embora a afirmação do crítico venha a ser atribuída a artistas, como Turner e Constable, que realizam pinturas ao gosto romântico da época, fica evidente que Bendito Calixto também utiliza delicadas pinceladas que enaltecem o entardecer nas marinhas, paisagens e arredores de Santos. Há um quê de melancólico na sua fatura, não se excede além da luz e seus matizes tonais. As obras Pescadores de cação e Canoas de Itanhaém, obras que fazem parte da coleção que compõem o acervo da Pinacoteca de Benedito Calixto (Santos), são referências da extensão de técnica acadêmica, mantendo o princípio do naturalismo na observação da luz e suas sombras visíveis, como na elaborada atmosfera realista. À primeira vista, o que pode ser observado é que o artista não subverte a ideia de que a paisagem obedece ao sentido e ao contraste da luz, e sim a ideia de uma pintura realizada ao "au plein air", que muitas vezes ou quase sempre obriga o pintor trabalhar um colorido feito sob o " olhar" de uma artista romântico. Essa linha difusa entre o romântico e o realista faz com o artista se notabilize e em suas produções temáticas.

Benedito Calixto instrumentaliza a história e a arquitetura para a manufatura de uma pintura da paisagem que permite e legitima a posse do território. A questão central reside na formação da identidade nacional; demonstrar o progresso científico e das artes aplicadas de um país recémimerso no sistema republicano. Aquelas paisagens não contam a história de uma natureza exótica; elas diziam sobre o avanço histórico e arquitetônico do povo paulista que institui uma tradição. $\mathrm{O}$ homem não é mais um dos elementos da natureza; ele interfere nela e a transforma. A paisagem

4 CLARK, Kenneth. Paisagem na arte. Trad. Rijo de Almeida. Lisboa: Ulisseia, 1961, p. 162. 
inóspita e selvagem em algo racional izado e civilizado. Na confecção das paisagens, o ato de mapear e de criar uma narrativa é transmitido às telas para a construção de um ideário indispensável para a “nova nação" brasileira, impulsionada pela coragem e pioneirismo dos paulistas.

Diga-se que muitos críticos e estudiosos veem como auge do percurso de Benedito Calixto as telas encomendadas pelo Museu Paulista, tidas como produto direto do empenho para a forja do passado "glorioso" de São Paulo. A eleição das fotografias de Militão feita por Taunay é bastante significativa na construção deste passado: das fotos selecionados para as matrizes da série de pinturas, onze pertencem ao Álbum Comparativo da Cidade de São Paulo (1862-1887) e cinco do álbum intitulado São Paulo Antigo. Segundo Lima e Carvalho (1993), de uma possibilidade de 60 fotos, Taunay seleciona apenas as parciais de 1862 que registram as ruas e os arredores do triângulo central da cidade - um recorte que claramente opta pelas ruas e vazios urbanos (sem a presença de transeuntes ou veículos). Essa seleção despreza todas as panorâmicas e, particularmente as imagens de 1887 (exceto a fotografia do Largo São Bento).

Desse conjunto de fotografias, surge uma cidade vazia, estável, sem qualquer sinal de crescimento ou transformação ${ }^{5}$. Mas, também espaços urbanos homogêneos e sem desestruturação. Essa organização espacial dada pela seleção das fotografias recebe ainda o tratamento idealizado do pintor Benedito Calixto. Tem-se como exemplo disto a tela Rua da Cruz Preta em 1858, quando o pintor prefere o registro da rua de terra batida às reformas para alinhamento e pavimentação que estão na fotografia de Militão. A subtração de elementos móveis, tais como, veículos e tipos humanos presentes nas fotografias, ocorre ainda na tela Rua da Quitanda em 1858.

Segundo Alexandre Eulálio ${ }^{6}$, há, ao menos, duas obras que integram o acervo do Museu de Arte Sacra e que são realizadas a partir das fotos de Militão. São elas: Recolhimento da Luz, fotografia feita por Militão em 1887 e Igreja do Brás em 1860, tela feita a partir da fotografia de 1862. Lembremos que algumas telas do Museu Paulista, particularmente as que retratam edifícios religiosos, são transferidas para a coleção do Museu da Cúria, além do acervo constituído por peças de igrejas demolidas ao longo do século XIX e peças doadas por artistas e colecionadores. Mencione-se ainda que no acervo do Museu Paulista, tem-se obras de Calixto que tratam sobre as paisagens do litoral de São Paulo, tal como Fundação de São Vicente, 1900 - considerada por muitos estudiosos como precursora do imaginário social brasileiro.

\footnotetext{
5 LIMA, S., e CARVALHO op. cit.

6 MUSEU DE ARTE SACRA. Mosteiro da Luz. Texto irmã Ruth Baggio, Benedito Lima de Toledo, Giselle Marques Leite Paixão, Maria Helena Brancante, Alexandre Eulálio, dom Clemente Maria da Silva-Nigra. São Paulo: Artes: SANBRA, 1987. 180 p., il. color. foto
} 
O tratamento da cor e da luz também são elementos diferenciais nessas pinturas. Em fins do século XIX, quando a pintura de paisagem cai no gosto burguês, até as primeiras duas décadas do século XX, os estudos da ação da luz sobre os objetos desenvolveram-se no sentido de representar o que seria a cor local, resultado da observação direta e da captação da luminosidade e colorido próprios do País. Nas pinturas encomendadas, percebe-se a densa atenção destinada ao cromatismo. Na representação da paisagem e dos aspectos arquitetônicos, o jogo entre áreas de luz e sombra sugere a relação harmoniosa da arquitetura colonial com o meio tropical brasileiro-aqui aponta-se a coexistência sem conflitos entre o núcleo urbano e o meio rural. Numa última camada de leitura, propõe-se uma transição continua e apaziguada entre o passado colonial e o presente modernizado.

Em síntese, nessa recriação visual da cidade colonial, a cidade moderna é a evolução consequente e surge como discurso de legitimação do poder político e econômico exercido pela elite cafeeira. Para os construtores do ideário da época, a "natural" aptidão do povo paulista para a liderança já se encontra no cerne daquela paisagem colonial - a crença na missão de conduzir a nação brasileira está presente nas telas de Benedito Calixto. Nas primeiras décadas da República, o lugar social do pintor encontra ressonância em ideias propagadas pelo IGHSP, responsável pela missão de recontar a história nacional, e pelo projeto visual organizado pelo Museu Paulista que visava a reconstituição do passado colonial de São Paulo. 


\section{Referências Biliográficas}

ALVES, Caleb Faria. Benedito Calixto e a construção do imaginário republicado. Bauru: EDUSC, 2003.

BANAT, Ana Kalassa el. A cidade pelos olhos do pintor: memória e representação de Santos em Benedito Calixto entre 1890 e 1927. Anais eletrônicos do XXII Encontro Estadual de História da ANPUH-SP, Santos, 2014. Disponível em http:// www.encontro2014.sp.anpuh.org/resources/anais/29/1406702320_ARQUIVO_CalixtoTEXTOANPUH.pdf. Acesso em 24 set. 2017

BANAT, Ana Kalassa. A construção da memória entre a fotografia e a pintura. Imaginário e representação nas imagens de Santos da segunda metade do século XX. Revista Ceciliana, mai. 2012. Disponível em www.unisanta.br/ revistaceciliana. Acesso em 24 abr. 2018.

CHIARELLI, Tadeu. Benedito Calixto: um pesquisador que pinta. In: CALIXTO, Benedito; SOUZA, Marli Nunes (coord.). Benedito Calixto: um pintor à beira-mar. Texto Caleb Faria Alves, Tadeu Chiarelli. São Paulo: Fundação Pinacoteca Benedicto Calixto, 2002.

CLARK, Kenneth. Paisagem na arte. Trad. Rijo de Almeida. Lisboa: Ulisseia, 1961.

FREITAS, Márcia de. Benedito Calixto no interior paulista. A Trombeta. 19 out. 2017.

LEITE, José Roberto Teixeira. Benedito Calixto: memória paulista. São Paulo: Banespa/Pinacoteca do Estado, 1990.

LIMA, S., e CARVALHO, V. São Paulo Antigo, uma encomenda da modernidade: as fotografias de Militão nas pinturas do Museu Paulista. Anais Do Museu Paulista: História ECultura Material, 1(1), 1993, p. 147-178.

MUSEU DE ARTE SACRA. Mosteiro da Luz. Texto irmã Ruth Baggio, Benedito Lima de Toledo, Giselle Marques Leite Paixão, Maria Helena Brancante, Alexandre Eulálio, dom Clemente Maria da Silva-Nigra. São Paulo: Artes: SANBRA, 1987. 180 p., il. color. foto.

OLIVEIRA, Emerson Dionisio G. de. Instituições, arte e o mito bandeirante: uma contribuição de Benedito Calixto. Seaculum (Revista de História). João Pessoa, jul./dez. 2008.

OLIVEIRA, Maria Alice Milliet de. Benedito Calixto: memória paulista. In: BENEDITO Calixto: memória paulista. São Paulo: Projeto Banespa, Pinacoteca do Estado, 1990, p. 19-21. 